\title{
PRINCÍPIO RESPONSABILIDADE E POLÍTICA DO DECRESCIMENTO: APROXIMAÇÕES E CONVERGÊNCIAS
}

\author{
The imperative of responsibility and the politics of decreasing: \\ Approaches and convergences
}

\author{
Mario Sergio Cunha Alencastro \\ Centro Universitário Internacional UNINTER \\ Mestrado em Educação e Novas Tecnologias \\ Eleandro de Souza Cabral \\ Centro Universitário Internacional UNINTER \\ Mestrado em Educação e Novas Tecnologias
}

RESUMO: A presente pesquisa tem como objetivo compreender abordagem temática sobre a "ética da responsabilidade" proposta pelo filósofo alemão Hans Jonas em sua mais influente obra: O Princípio Responsabilidade: Ensaio de uma ética para a civilização tecnológica, apresentando uma discussão acerca de como seus fundamentos ético-filosóficos se encontra em sintonia com a proposta política de decrescimento, assim como, em contrapartida demonstrar apontamentos pelos quais o autor se afasta das concepções do atual modelo de desenvolvimento sustentável. Esta pesquisa possui caráter bibliográfico, e efetiva uma análise acareando um posicionamento consequencialista frente ao descompasso entre a factual imprevisibilidade dos atos praticados pela humanidade e a degradação do meio ambiente promovida pela "Era da Civilização Tecnológica". Intenciona refletir sobre o posicionamento humano em relação à natureza ressaltando seu antropocentrismo exacerbado, perpassando a proposta de decrescimento como possibilidade de mediação responsável que atenda cuidados para com as gerações futuras e a vida planetária.

Palavras-chave: Hans Jonas; Responsabilidade; Decrescimento;

\section{INTRODUÇÃO}

A presente investigação emerge em um cenário global impactado pelo desequilíbrio ético da existência humana em relação aos seus pares enquanto partícipe de uma biosfera una, e é constituída em face da relevância apontada ao tema meio ambiente. Este mesmo ambiente sofre atualmente diversas alterações provenientes das ações imputadas pelo ser humano em seu habitat, o que denota um efeito rebote nocivo em face da vulnerabilidade deste ser e principalmente da natureza extra-humana. 
A capacidade humana de controlar e moldar o meio ambiente atribui ao contexto atual paradoxo insolúvel, no qual, na medida em que cresce a capacidade da técnica, maior se torna a deteriorização do nosso ambiente, e seus efeitos são agora atribuídos não somente a determinadas regiões ou populações, mas sim, se propagam e atingem a esfera global.

A delimitação do tema deste estudo decorre dos efeitos nocivos da Revolução Industrial e do empoderamento humano por meio da tecnologia, os quais denotam ao século XXI um legado que ameaça toda a sociedade contemporânea por meio da devastação ambiental.

Desta forma oportunizaremos neste estudo conhecer sobre a proposta Política de Decrescimento e seus principais pressupostos, tendo em vista a utilização descontrolada dos recursos não renováveis de nosso planeta. Pretende-se analisar o alinhamento da proposta Política do Decrescimento com os pressupostos da ética jonasiana, investigando como a articulação dessas duas teorias se relacionam e convergem para a ruptura com o antropocentrismo e a possibilidade de redução da produção e consumo ilimitado. Sabendo que estes dois fatores se apresentam como principal fator gerador da crise ambiental vivida pela civilização contemporânea, buscaremos possibilitar resposta à seguinte problemática: de que modo a fundamentação ético-filosóficos de Hans Jonas se encontram em maior sintonia com a proposta política de decrescimento e se afasta das concepções do atual modelo de desenvolvimento sustentável?

Fecharemos a circularidade do método argumentando sobre a sintonia existente entre a política do decrescimento e a ética da responsabilidade demonstrando que ambas alinhadas possuem fundamentação possível de auxiliar a civilização humana contemporânea construir condições de enfrentamento ao poder que hoje degrada nosso meio ambiente.

A hipótese apresentada, busca estruturar uma análise ontológica e ética que permita diálogo entre as respectivas teorias propondo um poder sobre o poder que faça frente aos anseios e desafios que esta nova sociedade experimenta.

\section{ONTOLOGIA SOBRE O DECRESCIMENTO}

O questionamento fundamental neste momento crítico não é mais apenas o ser humano, mas sim a vida como um sistema complexo interligado, onde a causa e efeito se tornam uma coisa somente. Jonas afirma que:

O futuro da humanidade é o primeiro dever do comportamento coletivo humano na idade da civilização técnica, que se tornou toda poderosa no que tange ao seu 
potencial de destruição. Esse futuro da humanidade inclui, obviamente, o futuro da natureza como sua condição "sine qua non"1 (JONAS, 2006, p.229).

O imperativo Jonasiano neste caso busca garantir a preservação das condições futuras para que a vida humana e extra-humana continue com sua autenticidade, referenciando a reciprocidade que deve haver entre elas. A grande provocação de Jonas está no dever, dever este nato em função do perigo, onde seu primeiro balbuciar está clamando por uma ética de preservação, e não por uma ética de progresso ou aperfeiçoamento (2006, p.232).

Quando a Política do Decrescimento trata solidariamente sobre o progresso, atribui à conotação de ateísmo econômico como uma forma de suspender a crença de que o crescimento é a alternativa e propósito último das sociedades. Faz-se necessário estar liberto da concepção de desenvolvimento e crescimento, entretanto, isto não implicam em renúncia as instituições sociais econômicas, mas sim, inseri-las em outra lógica que não seja a de produzir mais e consumir mais (LATOUCHE, 2010, p.19).

Este mundo, como montado, não se sustenta e o efeito rebote é o argumento central para o decrescimento, ou seja, a redução dos impactos ambientais não pode ser produzida sem uma diminuição do desenvolvimento econômico. Necessário se faz a redução da exploração dos recursos do planeta, pois como primeiro impacto terá a escassez da matéria prima, seguida pela inflação nos valores dos produtos, que por consequência reduzirá significativamente o poder de compra, gerando assim enorme estagnação econômica (BECK, 2010, p.241). O ponto crucial está em estabelecer ações verdadeiramente eficientes e preventivas, realocando o consumo para rumos que nos tragam benefícios ambientais.

\section{DECRESCIMENTO}

Decrescimento é uma linha de pensamento econômico e também político que teve sua origem na década de 1970, alicerçado nas teses do economista romeno, precursor da bioeconomia, Nicholas Georgescu-Roegen, as quais foram publicadas em sua obra The Entropy Law and the Economic Process (1971).

A teoria do decrescimento esta baseada na hipótese de que o crescimento econômico entendido também como aumento constante do Produto Interno Bruto (PIB) não é sustentável para o ecossistema global. Essa ideia é oposta ao pensamento econômico dominante, segundo o qual a melhoria do nível de vida seria decorrência do crescimento do PIB, e, assim, o aumento do valor da produção deveria ser um objetivo permanente da sociedade (LATOUCHE, 2006, p.19).

\footnotetext{
${ }^{1}$ Sine qua non ou conditio sine qua non é uma expressão que originou-se do termo legal em latim que pode ser traduzido como "sem a/o qual não pode ser". Refere-se a uma ação cuja condição ou ingrediente é indispensável e essencial.
} 
Para Serge Latouche a principal questão é a que os recursos naturais são limitados, e, portanto, não existe crescimento infinito. A melhoria das condições de vida deve, portanto, ser obtida sem aumento do consumo, mudando-se o paradigma dominante. O conceito de decrescimento não está pontuado em contrariedade ao consumo, já que seus fundamentos são propostos a partir do produtivismo, entretanto, afirma que não há nenhuma possibilidade de crescimento infinito num planeta finito (LATOUCHE, 2006, p.33). Serge Latouche opõe-se, portanto, ao consenso generalizado de que o crescimento econômico é o fundamento primeiro do bem-estar humano. Além disso, o aumento constante do PIB mundial por mais 50 anos, afetará a pegada ecológica da humanidade, que segundo ele, o impacto das nossas sociedades no ambiente já ultrapassa em quase 30\% a capacidade regenerativa do planeta.

Latouche (2006, p.36) quando aborda sobre o decrescimento afirma não se tratar de um estado estacionário como propostos em velhos clássicos, tão pouco uma forma de regressão, recessão ou crescimento negativo. Denota sim, que com todo rigor que deve ser entendido e chamado de acrescimento, fazendo menção ao ateísmo, pois em analogia contrária demonstra a fé e crença no PIB, em crescimento infinito, e na condição de solucionar problemas sociais apenas pelo viés econômico.

Sob o prisma proposto pela Política do Decrescimento, para que aconteça a conversão ecológica da economia, devemos reduzir o consumo e produção de acordo com as nossas necessidades reais, liberando tempo para investir em atividades criativas de riqueza social e ecológica. Em suma, devemos optar por cidadania, educação, justiça social e ambiental, em outras palavras, vamos apostar em viver melhor com menos. Latouche apregoa que se deve buscar o mesmo nível de satisfação sem a necessidade de recorrer ao sistema mercantilista, em suas próprias palavras: "El impacto es un retroceso del PIB y en consecuencia de la huella ecologica para mayor felicidad de todos (salvo tal vez para los comerciantes...)", (LATOUCHE, 2006, p.101).

Em continuidade afirma que não se deve entender o decrescimento como uma alternativa única e substituidora do modelo atual, mas um aviso sobre os riscos da situação em que vivemos, um grito por mudança. $\mathrm{O}$ decrescimento estaria para a humanidade como uma proteção mínima que possibilitaria iniciar a desconstrução do imaginário comum de que para avançar é necessário consumir.

Entende Latouche (2006, p.49) que o valor principal deva estar nas relações sociais e numa harmoniosa convivência de todos com a parte ecológica. Para tanto, faz-se necessário uma profunda mudança de valores.

\section{PRESSUPOSTOS DA TEORIA DO DECRESCIMENTO}


Além das considerações extraídas da experiência com o consumismo, Latouche traça determinadas linhas que devemos chamar de o fim econômico, pelo menos na acepção clássica do termo. A proposta do decrescimento aposta em uma economia desmaterializada, menos recursos naturais, bem mais uma economia de mobilização e conhecimentos especializados e bem menos de manipulação e transformação das matérias ponderáveis, o homem se tornará o centro desta proposta, entretanto, um centro como produção de valor (LATOUCHE, 2009, p. 115).

Latouche acredita que o PIB é uma medida apenas parcial da riqueza e que, se pretendemos restabelecer toda a variedade de riquezas possíveis, é preciso deixar de utilizá-lo como bússola. Assim, defende a utilização de outros indicadores, tais como o IDH, a Pegada

Ecológica e o Índice de Saúde Social, defende também, a revisão de conceitos como o desenvolvimento, o trabalho ou a riqueza, e o aprofundamento e resgate da justiça social, cidadania e democracia.

Ulrich Beck (2007, p.43) também teórico do decrescimento, descreve que o caracol constrói a sua concha somando, uma a uma, espirais cada vez maiores. E em determinado momento detém-se abruptamente e começa a fazer voltas decrescentes. Uma espiral a mais somente faria com que a concha fosse dezesseis vezes maior, sobrecarregando o animal. A partir daí, qualquer aumento da sua produtividade serviria somente para aliviar as dificuldades criadas por uma concha que crescera demais. Nesse limite, o problema do hiper-crescimento multiplicase em progressão geométrica, enquanto a capacidade biológica do caracol somente pode, no melhor dos casos, seguir uma progressão aritmética.

\section{CONSIDERAÇÕES FINAIS}

Em face ao cenário desafiador apresentado à contemporaneidade humana, este conferido pela crise ambiental instalada e pelo vazio ético encontrado nas mais diversas sociedades do planeta, é proposta uma ruptura com as propostas éticas tradicionais, a qual acontece em oportunidade da publicação de O Princípio Responsabilidade. O sistema ético encontrado até então, não trata da perspectiva dos seres humanos e não-humanos, mas sim, apenas de proposições voltadas ao relacionamento do indivíduo para com seus pares, a abertura desta nova proposta referencia Hans Jonas como marco fundamental na filosofia.

O núcleo da filosofia de Jonas se constitui em um necessário enfrentamento ao avanço tecnológico promovido pelas descobertas científicas e pelo avanço tecnológico humano, o qual detinha o controle sobre estas variáveis e a utilizava como meio para sua sobrevivência e comodidade. Em tempos atuais, e pela desenfreada busca por conhecimento, a humanidade sofre uma inversão entre os papéis que norteiam esta relação, a qual sai de detentora e controladora 
deste conhecimento, para objeto de manipulação e controlado. Jonas ao se defrontar com tal disparate propõe com extrema primazia uma ética que possibilite a não destruição humana, a preservação da natureza extra-humana e da manutenção das futuras gerações, entendendo não ser mais possível a regulação das ações do homem sob um prisma ético tradicional. Agrega a sua tese a necessidade de impreterivelmente não sujeitar a uma sorte temerária a biosfera planetária

Neste aspecto, a proposta da Política de Decrescimento de Serge Latouche ao se aliar a proposta do pensador alemão coadunará em fortalecer um pensamento ético de preservação planetária, a qual promoverá conscientização para cuidados com a biosfera de monta global.

Em resultado, o conjunto de partes coordenadas pelo consumismo insiste em não observar os assustadores sinais já emitidos pelo meio ambiente. O furor da técnica apresentada nesta pesquisa por meio de seu tentáculo mais subliminar, o consumo exacerbado, fomenta através de mecanismos e estratégias a sequência viciosa que manipula o indivíduo a sempre buscar a felicidade e o bem-estar na aquisição de bens. Entretanto, e como já vimos anteriormente, manifestadamente se consome recursos naturais não renováveis para esta produção

Sob o prisma da Política do Decrescimento tal problemática também é diagnosticada com formulação que transita sobre os mesmos trilhos de Hans Jonas, principalmente quando Serge Latouche aponta que a sociedade moderna utilize para uso próprio aproximadamente $30 \%$ a mais do que a biosfera é capaz de se regenerar, chegando ao ponto de sugerir inclusive a possibilidade de um o controle massivo da população ou a redução do consumo (LATOUCHE, 2009, p. 31).

A luz das afirmações de Jonas e Latouche, ambas apresentam convergências, visto a necessidade prática das teorias, Jonas define qual é objeto a ser defendido e quais os valores morais e éticos a serem utilizados e Latouche se manifesta apresentando como e onde atualmente o freio voluntário proposto pelo Princípio Responsabilidade encontrará resultado mais efetivo.

A proposta jonasiana trabalha a questão político ambiental trazendo inferências sobre o idealismo socialista e a democracia capitalista, mas de forma cautelosa não atribuí única e exclusivamente juízo de valor em ambos os sistemas (JONAS, 2006, p.241).

Mas ainda na esfera política Jonas invoca a responsabilidade política no papel do homem público, neste caso definido por ele como político e não pelo cargo técnico do funcionário, no qual menciona a potencialidade da missão deste homem quando identifica que fez o melhor que pode por aqueles sobre os quais detinha poder (JONAS, 2006, p.172).

$\mathrm{Na}$ visão de Serge Latouche a política fica incumbida de tratar de ações públicas que visem ao bem-estar das sociedades, primando pela construção de atitudes individuais formatadas em rede pensadas a partir de uma articulação aberta de movimento. Apresenta o capitalismo 
neoliberal elitista, assim como o socialismo partidário de massa, como precondições de continuidade para o avanço do consumo.

Através das perspectivas políticas apresentadas não encontramos isenção sobre o assunto, ambos pensadores se ocupam em desenvolver suas teorias propondo um determinado ceticismo perante aos sistemas de governo. Aperfeiçoam a questão da responsabilidade como um fenômeno integral de confluência entre seres humanos e meio ambientes.

Já na idéia de progresso o que movem as sociedades são os sonhos e as utopias projetadas por elas mesmas e seus esforços em transformá-las em realidade (BOFF, 2015, p.70). Neste aspecto o posicionamento de Hans Jonas e Serge Latouche estão alinhados perfeitamente por entenderem que não será possível a continuidade de crescimento mundial apenas pautado pelo bem-estar através do consumismo. Jonas se coloca da seguinte forma: "In Summa: em vez do crescimento, a palavra de ordem será a contração, algo muito mais difícil para os pregadores da utopia do que para os pragmáticos, desvinculados de ideologias”. (JONAS, 2006, p.265). Seguindo esta mesma linha de pensamento Latouche acredita que a riqueza produzida pelos sistemas econômicos não consiste apenas de bens e serviços, existem outras formas de riqueza social, tais como a educação, expectativa de vida, saneamento básico, moradia, transporte, saúde dos ecossistemas, a qualidade da justiça e das relações entre os membros de uma sociedade, o grau de igualdade e o caráter democrático das instituições. O crescimento da riqueza material, medido apenas por indicadores monetários, pode ocorrer em detrimento dessas outras formas de riqueza. Acredita que o PIB é uma medida apenas parcial da riqueza, e que, se pretendemos restabelecer toda a variedade de riquezas possíveis, é preciso deixar sua ideologia como bússola. Assim, defende a utilização de outros indicadores, tais como o IDH, a Pegada Ecológica e o Índice de Saúde Social (LATOUCHE, 2009, p. 139).

Ao tratarmos de uma suposição admissível futura de um desastre ambiental de proporções globais, abrimos caminho para análise da heurística do medo, nomeada por Jonas de futurologia comparativa (2006, p.70). Podemos compreender a terminologia mais defendida, Heurística do Temor, de forma ontológica, como sendo temor o sentimento que traz temor de algo ou alguém, e heurística como sendo a possibilidade de previsão ou temer determinada possibilidade (SÈVE, 1992, p.108, apud OLIVEIRA, 2014, p.133). Essa possibilidade buscará formar um arcabouço de saberes práticos em tempo presente sobre ações danosas e traçados perigosos que se encontram na esfera hipotética. Nesta abordagem Jonas busca formatar prognósticos partindo de pressupostos teóricos que transpasse e produza uma compassibilidade temerária que arregimente um medo ou temor (apesar de Jonas não distinguir didaticamente a 
diferença entre estes dois termos) que seja possível de desassimilação de um desejado resultado breve favorecendo determinado resultado de longo prazo (2006, p.74).

Em detrimento as éticas tradicionais, as quais laboram sobre pressupostos já experimentados, a ética da responsabilidade transita no âmbito exploratório de novas necessidades emergentes. Quando transpomos o foco de tal teoria para a análise do contexto ambiental marcado pelo consumismo antropocêntrico, nos deparamos com a complexidade da evolução humana e a imprevisibilidade que voeja sobre suas atitudes. Diante desta, Jonas aponta para uma proposta que busque identificar com antecedência a possibilidade de antever eventual deformação do homem, quando este aposta em ações sem a prévia análise futura das consequências, conforme suas próprias palavras: "só sabemos o que está em jogo quando sabemos que isto ou aquilo está em jogo" (2006, p.71). Jonas também ambiciona no sentido de que a incerteza dos prognósticos de longo prazo não possui possibilidade estática de ser dimensionada através de princípios da esfera dos fatos, os quais consideravam apenas aquilo que nos é próximo, deixando que o futuro cuidasse de si mesmo (2006, p.83). Ao concernir o progresso tecnológico e o consumismo humano crescente, o tratamento da incerteza nos obriga incondicionalmente em assumirmos a responsabilidade pelo que se apresentará como resultado de nossas ações, sendo então necessário através da heurística do temor tratar como certo o que se apresenta como duvidoso, primando sempre à possibilidade que previsionará o prognóstico com maior valor negativo, evitando assim arriscar interesses futuros se baseando fatos e riscos presentes, estaria tal ação comparada a construir um edifício sem escadas, visando futuramente suplantar a teoria da gravidade (2006, p.85).

Conforme posto anteriormente no corpo desta pesquisa, a política do decrescimento não está inerte a conjuctura dos riscos futuros e sua imprevisibilidade. Latouche afirma que mesmo que as eminentes catástrofes não abarcassem a destruição prevista, em seu prognóstico mais negativo, estas seriam promotoras de uma educação significativa em um conceito pedagógico, e trariam a pauta ensinamentos que relatariam os fatores de risco e os perigos do delírio produtivista (LATOUCHE, 2009, p. 95). Afirma ainda que ao mesmo tempo em que a debilitação do meio ambiente nos traz padecimento, também oportuniza as condições de conscientização. Nesta proposição Latouche entende a Heurística do Temor de Jonas como a necessidade de inserir no conjunto humano conteste os perigos ambientais eminentes, evitando assim um otimismo suicida da técnica e consumo. Latouche cita o filósofo francês Jean-Pierre Dupuy, que em sua a obra O Tempo das Catástrofes - quando o impossível é uma certeza (2011) afirma: "o que pode nos salvar é justamente o que nos ameaça". 
Na visão de Edgard Morin (2011, p.61) o qual se exprime de forma concludente com a formulação herança de morte para se direcionar a alusão da herança ofertada pelo século XX às sociedades contemporâneas, sabendo que este, trata sobre o aumento progressivo do poderio destruidor da técnica e consumo na transformação humana, que sobre uma perspectiva simplista pode nos levar sem a menor dúvida a uma morte ecológica.

Assim, a pesquisa em voga, por meio da sistematização dos assuntos elencados, busca desenvolver a possibilidade de reflexão junto à sociedade humana deste novo milênio, robustecendo cada indivíduo a tratar a problemática da técnica e consumo através de uma conotação ética que os liberte do ciclo vicioso ora instalado.

Insuflado por suas recorrentes descobertas seja perante o prolongamento da vida, o controle do comportamento humano ou a manipulação genética, o resgate do homo faber à sua condição de natureza se fará iniciado pela observância do próprio poder que o aprisiona. Neste caso o comportamento humano atribui força na movimentação da techné. Este comportamento por ser progenitor do circuito em que se autoderiva o indivíduo, deve ser trabalhado de forma se encontrar uma fenda na armadura onde se possibilitará libertar o objeto homo faber à reflexão, gerando assim a possibilidade de se frear o movimento doutrinador. Nas palavras de Hans Jonas (2006, p.91): "Pode-se dizer que os perigos que ameaçam o futuro modo de ser são, em geral, os mesmos que, em maior escala, ameaçam a existência; por isso, evitar os primeiros significa a fortiori evitar os outros".

Caberá então a filosofia oferecer ao ser humano orientação para o futuro, não mais travando uma inútil luta com os galhos, mas sabendo sim, que é no troco onde se encontra a tessitura do conjunto, no qual sua abertura através do conhecimento possibilitar-se-á a este refletir sobre sua condição moral frente às mudanças da natureza e sua preservação.

Mesmo uma sociedade inteira, uma nação, enfim, todas as sociedades contemporâneas tomadas em conjunto, não são proprietárias da terra. Elas são apenas ocupantes, usufrutuárias (Nutzniesser), e devem, como bons paters famílias, deixá-las em melhor estado para as futuras gerações (MARX, 1985, p.154).

Ao analisarmos o contexto sócio ambiental contemporâneo encontramos razões suficientes para revermos de forma contundente o atual modelo de desenvolvimento sustentável, o atual modelo de progresso e principalmente a cultura moral e ética hoje inseminada na humanidade. Latouche através da política do decrescimento, e esta, através de seu slogan provocador, que ao se justapor aos ateus da religião do crescimento, aos agnósticos do progresso, e principalmente orientada pelo princípio responsabilidade de Jonas, poderão aferir a possibilidade de enfrentamento da técnica transformadora. 


\section{REFERÊNCIAS}

ALENCASTRO, M.S.C. Ética e meio ambiente: construindo as bases para um futuro sustentável. Curitiba: InterSaberes, 2015.

BECK, U. GIDDENS, A. LASH, S. Modernização reflexiva: política, tradição e estética na ordem social moderna. São Paulo: Editora da Universidade Estadual Paulista, 1997.

BECK, U. Sociedade de risco: rumo a uma outra modernidade. Tradução de Sebastião Nascimento. São Paulo: Ed. 34; 2010.

BOFF, L. Sustentabilidade: o que é: o que não é. Rio de Janeiro: Vozes, 2012.

COMISSÃO DA CARTA DA TERRA. Carta da Terra. 2000. Disponível em: <http://www.earthcharter.org/files/charter/charter_po.pdf. Acesso em maio/2016.

EVANGELISTA, W. A renovação da teleologia em Hans Jonas: da biologia filosófica aos fundamentos da ética. Revista Princípios (UFRN), v.17, n.28, 2010.

HECK, J.N. O princípio responsabilidade e a teleologia objetiva dos valores. IN: SANTOS, Robinson dos (Org). Ética para a civilização tecnológica: Em diálogo com Hans Jonas. São Paulo: Ed. São Camilo, 2011.

JONAS, H. O princípio responsabilidade : ensaio de uma ética para a civilização tecnológica. Rio de Janeiro: PUC- Rio, 2006.

Vozes, 2004.

O princípio vida: Fundamentos para uma biologia filosófica. Petrópolis (RJ):

LATOUCHE, S. La apuesta por el decrecimiento. Cómo salir Del imaginario dominante? Barcelona: Icaria Editorial, 2006.

LATOUCHE, S. Farewell to Growth. Translated by David Macey. Cambridge: Polity Press, 2009.

LEFF, E. Saber ambiental: sustentabilidade, racionalidade, complexidade e poder. 2. ed. Petrópolis: Vozes, 2001.

MORIN, Edgard. Os sete saberes necessários à educação do futuro. 2. ed. São Paulo: Cortez; Brasília: UNESCO, 2011.

OLIVEIRA, J. Compreender Hans Jonas. Petrópolis: Vozes, 2014. - (Série compreender)

OLIVEIRA, J. SGANZERLA, A. e MORETTO, G. Vida, técnica e responsabilidade: três ensaios sobre a filosofia de Hans Jonas. São Paulo: Paulus, 2015. - (Coleção Ethos) 
ONU - ORGANIZAÇÕES DAS NAÇÕES UNIDAS. Objetivos do Milênio. 2000. Disponível em: <http://www.nospodemos.org.br/>. Acesso em: fevereiro/2016.

SGANZERLA, A. Natureza e responsabilidade : Hans Jonas e a biologização do ser moral. São Carlos: UFSC, 2012. 214 f. Tese 270 f. - Programa de Pós-Graduação em Filosofia, Universidade Federal de São Carlos Federal do Rio Grande do Sul, Porto Alegre, 1983, (Doutorado em Filosofia).

WORLDWATCH INSTITUTE - WWI. Estado do Mundo, 2010 - Transformando culturas: estadodo consumo e o consumo sustentável. Salvador: Uma Ed., 2010. Disponível em: <http://www.uma.org.br/estado_2015.pdf >. Acesso em: 11 mar. 2016. 